\title{
Effect of ovarian sympathectomy on follicular development during compensatory ovarian hypertrophy in the guinea-pig
}

\author{
T. E. Curry, Jr*, I. E. Lawrence, Jr and H. W. Burden \\ Department of Anatomy, East Carolina University, Greenville, NC 27834, U.S.A.
}

\begin{abstract}
Summary. Selective ovarian sympathectomy was achieved by injecting 6-hydroxydopamine into a surgically closed periovarian bursa on Day 3 of the oestrous cycle (Day $1=$ day of oestrus). Control ovaries had the periovarian bursa surgically closed and were injected with solvent. On Day 15 of the cycle, serum was collected for progesterone determination and ovaries were processed for morphometric analysis of follicles. In both control and sympathectomized ovaries remaining after unilateral ovariectomy on Day 3 , there was an increase in ovarian weight and an increase in healthy preovulatory follicles $(>700 \mu \mathrm{m}$ diam.). Sympathectomy of the ovary remaining after unilateral ovariectomy increased healthy follicles $510-700 \mu \mathrm{m}$ diameter but decreased the total number of follicles per ovary. In animals bearing both ovaries, unilateral sympathectomy did not affect any of the characteristics measured. Serum progesterone concentrations were unaffected by any of the treatments. These results indicate that adrenergic nerves play a role in follicular dynamics in ovaries undergoing compensatory hypertrophy but are not necessary for compensatory increases in weight and number of preovulatory follicles.
\end{abstract}

\section{Introduction}

Removal of one ovary causes a compensatory increase in the weight of the remaining ovary (compensatory ovarian hypertrophy) in the guinea-pig (Hermreck \& Greenwald, 1964). Ovarian nerves may participate in the development of compensatory hypertrophy after unilateral ovariectomy (Burden \& Lawrence, 1977; Gerendai, Marchetti, Mauger, Roxas \& Scapagnini, 1978; Gerendai \& Halasz, 1978; Gerendai, 1980). In the guinea-pig, the onset of the hypertrophy has been temporally associated with a decrease in the ovarian content of norepinephrine (Farrar, Handberg, Hartley \& Pennefather, 1980) and it was suggested that ovarian adrenergic nerves may normally exert a tonic inhibitory influence on the selection of follicles for maturation and/or ovulation.

The present study examined the role of ovarian adrenergic nerves in follicular development during compensatory hypertrophy after unilateral ovariectomy in the guinea-pig. Guinea-pigs were used because they have a dense ovarian adrenergic innervation and there have been no morphometric studies on the role of adrenergic nerves in compensatory follicular growth after unilateral ovariectomy.

* Present address: The Endocrine Laboratory, School of Medicine, University of Miami, Miami, FL 33101, U.S.A. 


\section{Materials and Methods}

Animals. Female Dunkin-Hartley guinea-pigs obtained from Dutchland Laboratories (Denver, Pennsylvania) were used. Animals were maintained on a $12 \mathrm{~h} \mathrm{light} / 12 \mathrm{~h}$ dark cycle and laboratory chow and water were provided ad libitum. The oestrous cycle was monitored by examining the vaginal membrane daily between $08: 00$ and 10:00 h and when patent a vaginal smear was taken. The day of maximal vaginal cornification was designated as the day of oestrus (Day 1 of the cycle).

General surgical techniques. Animals were initially anaesthetized with fentanylcitrate and droperidol ( $1 \mathrm{ml} / 10 \mathrm{~kg}$ i.m.; Innovar-Vet, Pitman-Moore, Inc., Washington Crossing, $\mathrm{NJ}$ ) and anaesthesia was maintained by exposure to methoxyflurane (Metofane, Pitman-Moore, Inc.) vapour with the aid of a nose cone. The ovaries were exposed by a dorsolateral flank incision. In the guinea-pig, both the mesotubarium superius (superior mesosalpinx) and the infundibular extremity of the oviducal mesenteries remain free from attachment forming an open periovarial sac (Beck, 1972). To provide a closed bursal cavity for local drug application, the free margin of the mesotubarium superius and infundibular oviducal mesentery was folded dorsolaterally to enclose the ovary and sutured to the mesometrial fat pad with 6-0 silk. Injections into the bursal cavity were accomplished with a 30-gauge needle fitted to a 5- $\mu$ l Hamilton syringe with the aid of a surgical microscope.

Validation of sympathectomy technique. The effectiveness of a closed bursal cavity for local drug application was evaluated in a preliminary study utilizing 6 guinea-pigs. One animal received $50 \mu l$ $1 \%$ toluidine blue in each closed bursal cavity. The bursal cavities and injection sites were observed for leakage for $15 \mathrm{~min}$ with a surgical microscope. 6-Hydroxydopamine is known to destroy adrenergic nerve terminals (Tranzer \& Thoenen, 1967; Thoenen \& Tranzer, 1968) and the remaining 5 guinea-pigs were used to check the effect of 6-hydroxydopamine injection into a surgically closed bursal sac on ovarian adrenergic nerves. A solution ( $15 \mathrm{mg}$ 6-hydroxydopamine $/ 50$ $\mu$ l) of 6-hydroxydopamine $(50 \mu \mathrm{l})$ was injected into one bursal cavity (experimental) and the contralateral cavity (control) was injected with $50 \mu 1$ solvent $(0.2 \%$ ascorbic acid in $0.9 \%(\mathrm{w} / \mathrm{v}) \mathrm{NaCl}$ ). Animals were killed $1,6,8,10$ or 12 days after injection and the ovaries were removed and processed for demonstration of adrenergic nerves (Falck \& Owman, 1965).

There was no evidence of leakage of the toluidine blue solution from the surgically closed bursal cavity during the 15 -min observation period. Injection of $50 \mu 16$-hydroxydopamine into the bursal cavity caused a complete disappearance of ovarian fluorescent adrenergic nerves within $24 \mathrm{~h}$ and there were no fluorescent nerves present at 6 and 8 days after sympathectomy. Ten and 12 days after injection of 6-hydroxydopamine into the bursal cavity, a few faint perivascular fluorescent nerves were present but non-perivascular nerves were not observed. Brightly fluorescent nerves were present in the contralateral solvent-injection ovary at all days after injection. Therefore we concluded that injection of 6-hydroxydopamine into a surgically closed ovarian bursa was a reliable method to sympathectomize the ovary.

Effect of ovarian sympathectomy on compensatory ovarian hypertrophy. Adult guinea-pigs (500$780 \mathrm{~g}$ ) were divided into 5 groups as follows: Group $1(\mathrm{~N}=7)$, unilaterally ovariectomized and the remaining ovary left intact; Group $2(\mathrm{~N}=7)$, unilaterally ovariectomized and the bursa of the remaining ovary surgically closed and injected with $50 \mu \mathrm{l}$ solvent $(0.2 \%$ ascorbic acid in $0.9 \%$ $\mathrm{NaCl})$; Group $3(\mathrm{~N}=8)$, unilaterally ovariectomized and the bursa of the remaining ovary surgically closed and injected with $50 \mu \mathrm{l}$ 6-hydroxydopamine $(15 \mathrm{mg} / 50 \mu \mathrm{l})$; Group $4(\mathrm{~N}=7)$, the ovarian bursa was sewn closed on one side and injected with $50 \mu \mathrm{l}$ solvent while the other ovary was left intact; Group $5(\mathrm{~N}=9)$, the bursa was closed on one side and injected with $50 \mu 16$ hydroxydopamine $(15 \mathrm{mg} / 50 \mu \mathrm{l})$ while the other ovary was left intact.

The selection of ovaries for treatment in each group was alternated between left and right sides 
in different animals. All surgery and injections into the bursal cavity were performed on Day 3 of the oestrous cycle. Unilateral ovariectomy at this time results in a maximal compensatory response in the remaining ovary (Hermreck \& Greenwald, 1964). On the morning of Day 15, animals in Groups 1, 2 and 3 were decapitated and trunk blood was collected. Guinea-pigs in Groups 4 and 5 were laparotomized and utero-ovarian vein blood samples were taken bilaterally. Serum samples were stored at $-20^{\circ} \mathrm{C}$ for up to 3 months before analysis of progesterone concentrations. The ovaries were removed from all animals, embedded in paraffin wax, serially sectioned at $8 \mu \mathrm{m}$ and processed for haematoxylin and eosin (H \& E) staining. Corpora lutea (CL) and follicles were counted in every fifth section. Follicles with oocytes containing nuclei were classified as preantral (characterized by two or more layers of granulosa cells without cavitation) or antral and as healthy or atretic (defined as follicles with at least 5 granulosa cells with pycnotic nuclei). Two measurements at right angles were made of the diameter of each follicle. The mean of these measurements was used to assign follicles to one of four size groups: 140-300, 310-500, 510-700 and $>700 \mu \mathrm{m}$. Numbers of preantral and antral follicles in the different size groups were expressed as a percentage of the total follicular population in the ovary.

Progesterone radioimmunoassay. Serum concentrations of progesterone (4-pregnen-3,20-dione) were determined in duplicate by radioimmunoassay procedures previously validated in our laboratory (Burden, Lawrence, Louis \& Hodson, 1981). The antiserum was raised in rabbits to progesterone-1 $1 \alpha$-BSA (Miles Laboratories, Elkhart, Indiana, U.S.A.). The only significant crossreactivities of the antiserum were with $11 \alpha$-hydroxyprogesterone and $11 \beta$-hydroxyprogesterone (44 and $8 \%$ respectively). The antiserum also cross-reacted with $5 \alpha$-pregnen- 3,20 -dione $(3 \%)$ and with $17 \alpha$-hydroxyprogesterone $(2 \%)$. Cross-reactions with all other possible interfering steroids were $<0.4 \%$.

The assay sensitivity was $10 \mathrm{pg} / \mathrm{tube}(100 \mathrm{pg} / \mathrm{ml})$ with a blank of $5-6 \mathrm{pg}$. Intra- and inter-assay coefficients of variation were 12.8 and $17.3 \%$ respectively. The overall inter-assay recovery was $81 \cdot 9 \%$.

Statistics. Raw data were tested for homogeneity of variance and normal distribution with Bartlett's $\chi^{2}$ and the Kolmogorov-Smirnov goodness-of-fit test respectively (Zar, 1974). An analysis of variance (ANOVA) was used to test differences in follicular development and progesterone levels. If significance was obtained with ANOVA, the Student-Newman-Keul's procedure was used for group comparisons.

\section{Results}

Effect of ovarian sympathectomy on compensatory ovarian hypertrophy

All the animals in Groups 1,2 and 3 exhibited significant $(P<0.02)$ compensatory hypertrophy of the remaining ovary (Table 1). In animals bearing both ovaries, injection of solvent (Group 4) or

Table 1. The effect of sympathectomy on ovarian weight 12 days after unilateral ovariectomy in the guinea-pig

\begin{tabular}{|c|c|c|c|c|}
\hline \multirow[b]{2}{*}{ Group } & \multirow[b]{2}{*}{ Treatment } & \multirow{2}{*}{$\begin{array}{l}\text { No. of } \\
\text { animals }\end{array}$} & \multicolumn{2}{|c|}{$\begin{array}{c}\text { Wt of ovary } \\
\text { (mg/100 g body wt) }\end{array}$} \\
\hline & & & Initial & Remaining \\
\hline 1 & None & 7 & $5.6 \pm 0.4$ & $7 \cdot 2 \pm 0.5^{*}$ \\
\hline 2 & Solvent & 7 & $6.2 \pm 0.6$ & $8 \cdot 6 \pm 0.6^{*}$ \\
\hline 3 & 6-Hydroxydopamine & 8 & $5.5 \pm 0.6$ & $7 \cdot 8 \pm 0.7^{*}$ \\
\hline
\end{tabular}


Table 2. The effect of ovarian sympathectomy on follicular development in guinea-pigs 12 days after unilateral ovariectomy

\begin{tabular}{|c|c|c|c|c|c|c|c|c|c|c|}
\hline \multirow[b]{3}{*}{ Group } & \multirow{3}{*}{$\begin{array}{c}\text { Total } \\
\text { no. of } \\
\text { follicles }\end{array}$} & \multirow{3}{*}{$\begin{array}{l}\text { Preantral } \\
\text { follicles }\end{array}$} & \multicolumn{8}{|c|}{ Antral follicle diameter $(\mu \mathrm{m})$} \\
\hline & & & \multicolumn{2}{|c|}{$140-300$} & \multicolumn{2}{|c|}{$310-500$} & \multicolumn{2}{|c|}{$510-700$} & \multicolumn{2}{|c|}{$>700$} \\
\hline & & & Healthy & Atretic & Healthy & Atretic & Healthy & Atretic & Healthy & Atretic \\
\hline 1 & $222 \pm 78 \cdot 6^{a}$ & $\begin{array}{c}34 \cdot 3 \pm 1 \cdot 9 \\
(76 \cdot 2 \pm 4 \cdot 2)\end{array}$ & $\begin{array}{c}17 \cdot 2 \pm 1 \cdot 2 \\
(38 \cdot 2 \pm 2 \cdot 7)\end{array}$ & $\begin{array}{c}26 \cdot 2 \pm 1 \cdot 3 \\
(58 \cdot 2 \pm 2 \cdot 9)\end{array}$ & $\begin{array}{c}5 \cdot 3 \pm 1 \cdot 2 \\
(11 \cdot 8 \pm 2 \cdot 7)\end{array}$ & $\begin{array}{c}9 \cdot 1 \pm 1 \cdot 0 \\
(20 \cdot 2 \pm 2 \cdot 2)\end{array}$ & $\begin{array}{c}0.2 \pm 0.2 \\
(0.4 \pm 0.4)^{2}\end{array}$ & $\begin{array}{c}4.9 \pm 0.8 \\
(10.9 \pm 1 \cdot 8)\end{array}$ & $\begin{array}{c}2.7 \pm 0.8 \\
(6.0 \pm 1 \cdot 8)^{3}\end{array}$ & $\begin{array}{c}0.3 \pm 0.1 \\
(0.5 \pm 0.2)\end{array}$ \\
\hline 2 & $282 \cdot 6 \pm 40 \cdot 8^{a}$ & $\begin{array}{c}27.9 \pm 2.8 \\
(78.9 \pm 7.9)\end{array}$ & $\begin{array}{c}20.9 \pm 4.2 \\
(59 \cdot 1 \pm 11.9)\end{array}$ & $\begin{array}{c}25 \cdot 2 \pm 3 \cdot 7 \\
(71 \cdot 2 \pm 10 \cdot 5)\end{array}$ & $\begin{array}{c}6 \cdot 2 \pm 1 \cdot 0 \\
(17 \cdot 5 \pm 2 \cdot 8)\end{array}$ & $\begin{array}{c}10 \cdot 7 \pm 2 \cdot 2 \\
(30 \cdot 2 \pm 6 \cdot 2)\end{array}$ & $\begin{array}{c}1.2 \pm 0.5 \\
(3.4 \pm 1 \cdot 4)^{3.6}\end{array}$ & $\begin{array}{c}5 \cdot 1 \pm 1 \cdot 3 \\
(14 \cdot 4 \pm 3 \cdot 7)\end{array}$ & $\begin{array}{c}2 \cdot 0 \pm 0.3 \\
(5 \cdot 7 \pm 0 \cdot 9)^{a}\end{array}$ & $\begin{array}{c}0.7 \pm 0.3 \\
(2.0 \pm 0.9)\end{array}$ \\
\hline 3 & $109 \cdot 8 \pm\left[1.4^{b}\right.$ & $\begin{array}{c}31 \cdot 0 \pm 1 \cdot 8 \\
(34 \cdot 0 \pm 2 \cdot 0) \\
\end{array}$ & $\begin{array}{c}17.9 \pm 3.6 \\
(19.7 \pm 4.0)\end{array}$ & $\begin{array}{c}20.5 \pm 4.4 \\
(22.5 \pm 4.9)\end{array}$ & $\begin{array}{c}4.3 \pm 0.8 \\
(4 \cdot 7 \pm 0.9)\end{array}$ & $\begin{array}{c}11 \cdot 2 \pm 1 \cdot 2 \\
(12 \cdot 3 \pm 1 \cdot 3)\end{array}$ & $\begin{array}{c}4 \cdot 0 \pm 1 \cdot 2 \\
(4 \cdot 4 \pm 1 \cdot 3)^{b}\end{array}$ & $\begin{array}{c}6 \cdot 6 \pm 1 \cdot 7 \\
(7 \cdot 2 \pm 1 \cdot 9)\end{array}$ & $\begin{array}{c}4 \cdot 1 \pm 1 \cdot 2 \\
(4 \cdot 5 \pm 1 \cdot 3)^{a}\end{array}$ & $\begin{array}{c}0.5 \pm 0.2 \\
(0.6 \pm 0.2)\end{array}$ \\
\hline 4 & $189 \cdot 8 \pm 75 \cdot 7^{\mathrm{a} \cdot \mathrm{b}}$ & $\begin{array}{c}34 \cdot 7 \pm 2 \cdot 2 \\
(65 \cdot 9 \pm 4 \cdot 2)\end{array}$ & $\begin{array}{c}14 \cdot 8 \pm 2 \cdot 8 \\
(28 \cdot 1 \pm 5 \cdot 3)\end{array}$ & $\begin{array}{c}27.7 \pm 3 \cdot 5 \\
(52 \cdot 6 \pm 6.6) \\
\end{array}$ & $\begin{array}{c}5.8 \pm 0.8 \\
(11.0 \pm 1.5) \\
\end{array}$ & $\begin{array}{c}10 \cdot 8 \pm 0.9 \\
(20.5 \pm 1 \cdot 7)\end{array}$ & $\begin{array}{c}1.0 \pm 0.4 \\
(1.9 \pm 0.8)^{a, b}\end{array}$ & $\begin{array}{c}3 \cdot 8 \pm 1 \cdot 1 \\
(7 \cdot 2 \pm 2 \cdot 1)\end{array}$ & $\begin{array}{c}1 \cdot 1 \pm 0 \cdot 2 \\
(2 \cdot 1 \pm 0 \cdot 4)^{b}\end{array}$ & $\begin{array}{c}0.3 \pm 0.2 \\
(0.6 \pm 0.4) \\
\end{array}$ \\
\hline 5 & $130 \cdot 5 \pm 42 \cdot 7^{a, b}$ & $\begin{array}{c}31 \cdot 3 \pm 1 \cdot 8 \\
(40 \cdot 9 \pm 2 \cdot 4)\end{array}$ & $\begin{array}{c}15 \cdot 3 \pm 4 \cdot 8 \\
(20 \cdot 0 \pm 6 \cdot 3)\end{array}$ & $\begin{array}{c}28 \cdot 6 \pm 4 \cdot 2 \\
(37 \cdot 3 \pm 5 \cdot 5)\end{array}$ & $\begin{array}{c}4.0 \pm 1 \cdot 5 \\
(5 \cdot 2 \pm 2.0)\end{array}$ & $12 \cdot 1 \pm 1 \cdot 3$ & $\begin{array}{c}0 \cdot 1 \pm 0 \cdot 1 \\
(0 \cdot 2 \pm 0 \cdot 1)^{a}\end{array}$ & $\begin{array}{c}4 \cdot 8 \pm 1 \cdot 2 \\
(6 \cdot 3 \pm 1 \cdot 6)\end{array}$ & $\begin{array}{c}1.7 \pm 0.8 \\
(1.8 \pm 0.3)^{b}\end{array}$ & $\begin{array}{c}1.2 \pm 0.5 \\
(1.6 \pm 0.7)\end{array}$ \\
\hline
\end{tabular}

Values are mean \pm s.e.m. (expressed as a percentage of the total no. of follicles with no. in parentheses), 5 ovaries/group.

Values with different superscripts in the same column are significantly different $(P<0.05)$.

6-hydroxydopamine (Group 5) had no effect on ovarian weight $(7 \cdot 2 \pm 0.9$ and $7.6 \pm 1.2 \mathrm{mg} / 100 \mathrm{~g}$ body wt in Group 4 and $6.8 \pm 0.6$ and $7.2 \pm 0.7 \mathrm{mg} / 100 \mathrm{~g}$ body wt in Group 5). The analysis of follicular number and size distribution is given in Table 2. Unilateral ovariectomy increased the number of healthy follicles $>700 \mu \mathrm{m}$ diameter $(P<0.05)$ and local 6-hydroxydopamine administration did not alter this effect. In unilaterally ovariectomized animals, local application of 6-hydroxydopamine to the remaining ovary significantly $(P<0.05)$ increased the number of healthy 510-700 $\mu \mathrm{m}$ follicles but decreased $(P<0.05)$ the total number of follicles per ovary. In animals bearing both ovaries, unilateral ovarian sympathectomy did not affect ovarian weight, total number of follicles per ovary or follicles in any size classification.

\section{Effect of ovarian sympathectomy on serum progesterone levels}

In animals in Groups 1, 2 and 3, injection of solvent or 6-hydroxydopamine into the bursal cavity of the remaining ovary did not affect trunk serum progesterone levels (Text-fig. 1). In animals with both ovaries (Groups $4 \& 5$ ), there was no effect of intrabursal solvent or 6-hydroxydopamine on progesterone concentrations.

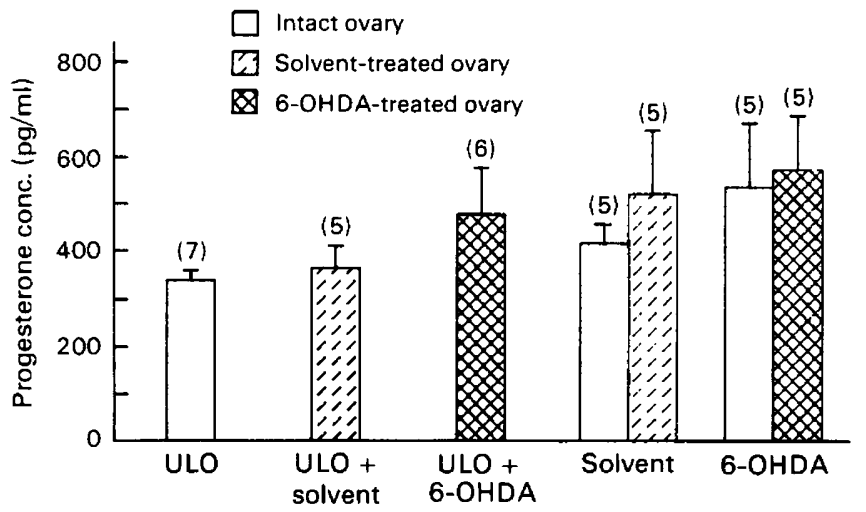

Text-fig. 1. Mean ( \pm s.e.m.) progesterone concentrations in guinea-pigs (no. in parentheses) after sympathectomy or unilateral ovariectomy (ULO) + sympathectomy (6-OHDA). 


\section{Discussion}

Removal of one ovary causes a compensatory increase in the weight of the remaining ovary. The increased weight is attributable to an 'increased rate of transformation of smaller sized follicles to larger ones' (Hermreck \& Greenwald, 1964). Investigators have suggested a role for nerves in compensatory ovarian hypertrophy in the rat (Burden \& Lawrence, 1977; Gerendai et al., 1978; Gerendai \& Halasz, 1978; Gerendai, 1980). Gerendai \& Halasz (1978) postulated the existence of a gonadal-hypothalamic neural axis or 'neural reflex mechanism' which is required for development of the hypertrophy. This 'neural reflex mechanism' would mediate an afferent signal from the extirpated or damaged ovary to produce the efferent response for hypertrophy in the contralateral ovary. As an example, compensatory changes after unilateral ovariectomy in the rat were prevented by encapsulating and exposing the remaining ovary to 6-hydroxydopamine (Gerendai $e t$ al., 1978). These workers showed that, in rats with both ovaries, local treatment of one ovary with 6hydroxydopamine resulted in a significant weight gain in the contralateral ovary. We were unable to confirm the existence of a 'neural reflex mechanism' for the development of compensatory ovarian hypertrophy in the guinea-pig even though we administered a 5-fold greater concentration of 6-hydroxydopamine than did Gerendai et al. (1978). In the present study, by 12 days after unilateral ovariectomy, the remaining ovary, whether sympathectomized or solvent-treated, was significantly heavier than the ovary removed at surgery. Morphometric analysis of the remaining ovary showed a doubling of large preovulatory follicles in these animals. In guinea-pigs bearing both ovaries, local 6-hydroxydopamine treatment did not induce compensatory responses in the contralateral intact ovary. These observations are dissimilar to previous reports for the rat (Gerendai et al., 1978; Gerendai \& Halasz, 1978). The efficacy of the present ovarian sympathectomy technique has been demonstrated by fluorescence microscopy. The degree of ovarian sympathectomy in the study of Gerendai et al. (1978) was not assessed. These dissimilarities in development of compensatory ovarian hypertrophy after treatment with 6hydroxydopamine may be related to differences in the density of ovarian adrenergic nerves in the two species.

The neural influence on ovarian follicular development in guinea-pigs differs after removal of one ovary compared to animals bearing both ovaries. Sympathectomy of the ovary remaining after unilateral ovariectomy increased the number of healthy follicles in the $510-700 \mu \mathrm{m}$ group. During compensatory hypertrophy, ovarian adrenergic nerves may exert an inhibitory influence on the growth of large antral follicles. Also, sympathectomy of the ovary remaining after unilateral ovariectomy caused a decrease in the total number of preantral and antral follicles. In animals bearing both ovaries, sympathectomy of one ovary did not affect follicular development or the total number of follicles at any day of the oestrous cycle. We suggest that when both ovaries are present hormones control follicular development. When one ovary is removed, the hormonal milieu is altered and nerves influence follicular growth.

In our preliminary studies we observed a few, faint perivascular adrenergic nerves regenerating 12 days after injection of 6-hydroxydopamine into the surgically closed ovarian bursa. In the experiments reported here, there was also a 12-day interval after ovarian sympathectomy. Thus, it cannot be assumed that the sympathectomized ovaries in the present study were completely devoid of noradrenaline.

Progesterone production has been reported to be stimulated by catecholamines (Condon \& Black, 1976; Jordan, Chaffrey \& Niswender, 1978; Ratner, Sanborn \& Weiss, 1980; Adashi \& Hseuh, 1981 ; Zsolnai, Varga \& Horvath, 1982). In the present study, removal of ovarian adrenergic nerves at Day 3 of the cycle did not alter progesterone concentrations at Day 15, a period when progesterone production is low (Joshi, Watson \& Labhsetwar, 1973; Blatchley, Donovan \& ter Haar, 1976). Likewise, unilateral sympathectomy in animals with two ovaries did not affect trunk blood levels of progesterone at this time. We suggest that the influence of catecholamines on progesterone production is minimal when production of this hormone is at basal levels. 
We conclude that an intact adrenergic innervation is not prerequisite for the compensatory increase in weight of the remaining ovary after unilateral ovariectomy in the guinea-pig. However, removal of adrenergic nerves in the remaining ovary after unilateral ovariectomy does alter the follicle populations normally seen in ovaries undergoing compensatory hypertrophy.

The study was supported in part by grant HD 06899 from the National Institute of Child Health and Human Development. We thank Alma Haddock and Shirley Nett for help with the manuscript.

\section{References}

Adashi, E.Y. \& Hsueh, A.J. (1981) Stimuation of $\beta$ adrenergic responsiveness by follicle stimulating hormone in rat granulosa cells in vitro and in vivo. Endocrinology 108, 2170-2178.

Beck, L.R. (1972) Comparative observations on the morphology of the mammalian periovarial sac. $J$. Morph. 136, 247-254.

Blatchley, F.R., Donovan, B.T. \& ter Haar, M.B. (1976) Plasma progesterone and gonadotropin levels during the estrous cycle of the guinea pig. Biol. Reprod. 15, 29-38.

Burden, H.W. \& Lawrence, I.E., Jr (1977) The effect of denervation on compensatory ovarian hypertrophy. Neuroendocrinology 23, 368-378.

Burden, H.W., Lawrence, I.E., Jr, Louis, T.M. \& Hodson, C.A. (1981) Effects of abdominal vagotomy on the estrous cycle of the rat and the induction of pseudopregnancy. Neuroendocrinology 33, 218-222.

Condon, W.A. \& Black, D.L. (1976) Catecholamineinduced stimulation of progesterone by the bovine corpus luteum in vitro. Biol. Reprod. 15, 573-578.

Falck, B. \& Owman, C. (1965) A detailed methodological description of the fluorescence method for the cellular demonstration of biogenic monamines. Acta Univ. lund. 7, 1-23.

Farrar, J.A., Handberg, G.M., Hartley, M.L. \& Pennefather, J.N. (1980) Catecholamine levels in the guinea pig ovary, myometrium and costo-uterine muscle during the estrous cycle and in the ovary remaining after unilateral ovariectomy. Biol. Reprod. 22, 473479.

Gerendai, I. (1980) Unilateral complete isolation of the medial basal hypothalamus interferes with the compensatory ovarian growth following unilateral ovariectomy. Neuroendocr. Lett. 2, 39-43.

Gerendai, I. \& Halasz, B. (1978) Neural participation in ovarian control. TINS 1, 87-88.
Gerendai, I., Marchetti, B., Mauger, S., Roxas, M.A. \& Scapagnini, U. (1978) Prevention of compensatory ovarian hypertrophy by local treatment of the ovary with 6-hydroxydopamine. Neuroendocrinology 27, 272-278.

Hermreck, A.S. \& Greenwald, G.S. (1964) The effects of unilateral ovariectomy on follicular maturation in the guinea pig. Anat. Rec. 148, 171-176.

Jordan, A.W., Chaffrey, J.L. \& Niswender, G.D. (1978) Catecholamine-induced stimulation of progesterone and adenosine $3^{\prime}, 5^{\prime}$-monophosphate production by dispersed ovine luteal cells. Endocrinology 103, 385392.

Joshi, H.S., Watson, D.J. \& Labhsetwar, A.P. (1973) Ovarian secretion of oestradiol, oestrone, 20-dihydroprogesterone and progesterone during the oestrous cycle of the guinea-pig. J. Reprod. Fert. 35, 177-181.

Ratner, A., Sanborn, C.R. \& Weiss, G.K. (1980) $\beta$ adrenergic stimulation of CAMP and progesterone in rat ovarian tissue. Am. J. Physiol. 293, E139-E143.

Thoenen, H. \& Tranzer, J.P. (1968) Chemical sympathectomy by selective destruction of adrenergic nerve endings with 6-hydroxydopamine. Naunyn-Schmiedebergs Arch. exp. Path. Pharmak. 261, 271-288.

Tranzer, J.P. \& Thoenen, H. (1967) Ultra-morphologische Veranderungen der Sympathischen Nervendigungen der Katze nach Vorbehandlung mit 5- und 6hydroxydopamine. Naunyn-Schmiedebergs Arch. exp. Path. Pharmak. 257, 343-344.

Zar, J.H. (1974) Biostatistical Analysis. Prentice-Hall Inc., Englewood Cliffs.

Zsolnai, B., Varga, B. \& Horvath, E. (1982) Increase of ovarian progesterone secretion by $\beta_{2}$-adrenergic stimulation in oestrous rats. Acta endocr., Copenh. 101, 268-272.

Received 1 July 1983 